\title{
Advanced Real Time Optical Imaging: Part II
}

\author{
JINICHIRO NAKANO ${ }^{1,2,3}$ \\ 1.-US Department of Energy National Energy Technology Laboratory, 1450 Queen Ave, \\ Albany, OR 97321, USA. 2.-AECOM, P.O. Box 618, South Park, PA 15129, USA. 3.-e-mail: \\ jinichiro.nakano@netl.doe.gov
}

The first segment of this special topic, Advanced Real-time Optical Imaging: Part I (July 2018), featured a variety of studies based on techniques including hot thermocouple, particle image velocimetry, high-speed camera, infrared imaging, and environmental confocal scanning laser microscopy. The papers contributed by experts in each field re-emphasized the significance of real-time optical imaging in materials science and processing. Emerging, traditional, and mixed imaging techniques were presented describing creative and innovative methods of real-time materials investigations. Part II follows the same goal as the first segment: that advanced realtime optical imaging techniques are assembled in a single venue to emphasize the diversity and strength of these approaches.

In recognition of materials and processing studies utilizing unconventional imaging techniques, the symposium Advanced Real Time Optical Imaging was initiated at the TMS 2018 Annual Meeting and Exhibition (TMS2018) in Phoenix, AZ. The symposium was well received, and the decision was made to continue it as an annual assembly at future TMS meetings. The next Advanced Real Time Imaging symposium will take place at the TMS 2019 Annual Meeting and Exhibition (TMS2019) in San Antonio, TX. About 50 papers featuring various advanced real-time imaging techniques are anticipated, presenting pioneering findings from those approaches. Note that 'optical' has been removed from the symposium title following suggestions and requests from the participants to accommodate a broader range of techniques. Interested researchers are encouraged to attend the symposium.

The impact of the advanced real-time optical imaging techniques on modern materials and pro-

\footnotetext{
Jinichiro Nakano is a guest editor for the Advanced Characterization, Testing, and Simulation Committee of the TMS Functional Materials Division and also for the Alloy Phases Committee of the TMS Structural Materials Division (SMD), and coordinator of the topic Advanced Real Time Optical Imaging: Part II in this issue.
}

cessing studies was discussed in Part I, based on statistics in publications and citations. Since the onset of the rapid rise in publications featuring realtime imaging in 1990, the number has continued to increase, reflecting the topic's significance. According to the Clarivate Analytics Web of Science (Analytics), the total number of such papers reached 49,349 in July 2018. Approximately 4000 publications per year emphasized real-time optical imaging techniques in 2015-2017. The number of citations of such papers shows the exponential growth (Fig. 1). In the field of Metallurgy, 873 papers were cited in 2017, with 632 papers cited in Energy and Fuels in the same year. The importance of real-time imaging in studies of materials and processes is apparent and is expected to continue into the future.

The following papers are published on the topic "Advanced Real Time Optical Imaging: Part II" in the October 2018 issue (vol. 70, no. 10) of JOM and can be accessed via the $J O M$ page at http://link.sp ringer.com/journal/11837/70/10/page/1.

\section{HIGH-SPEED CAMERA TECHNIQUE}

- "In-Situ Investigation of Slag-Metal Interactions in Ld Converter upon Low Voltage Application" by S.I. Semykin and T.S. Golub.

\section{'MECHANICAL' CONFOCAL SCANNING LASER MICROSCOPY}

- "Use of Confocal Microscope for Environmental Tensile Mechanical Testing" by K.A. Rozman, W.H.H. Nealley, J. Nakano, S.R. Akanda, Ö.N. Doğan, and J.A. Hawk.

- "Assessing Mechanical Behaviors of Additive Manufactured Alternating Layers of Inconel718/H13 Tool Steel: imaging the crack initiation and propagation" by B. E. Tucker, W. H. H. Nealley, B. Dutta, J. Nakano, and D. Maurice. 

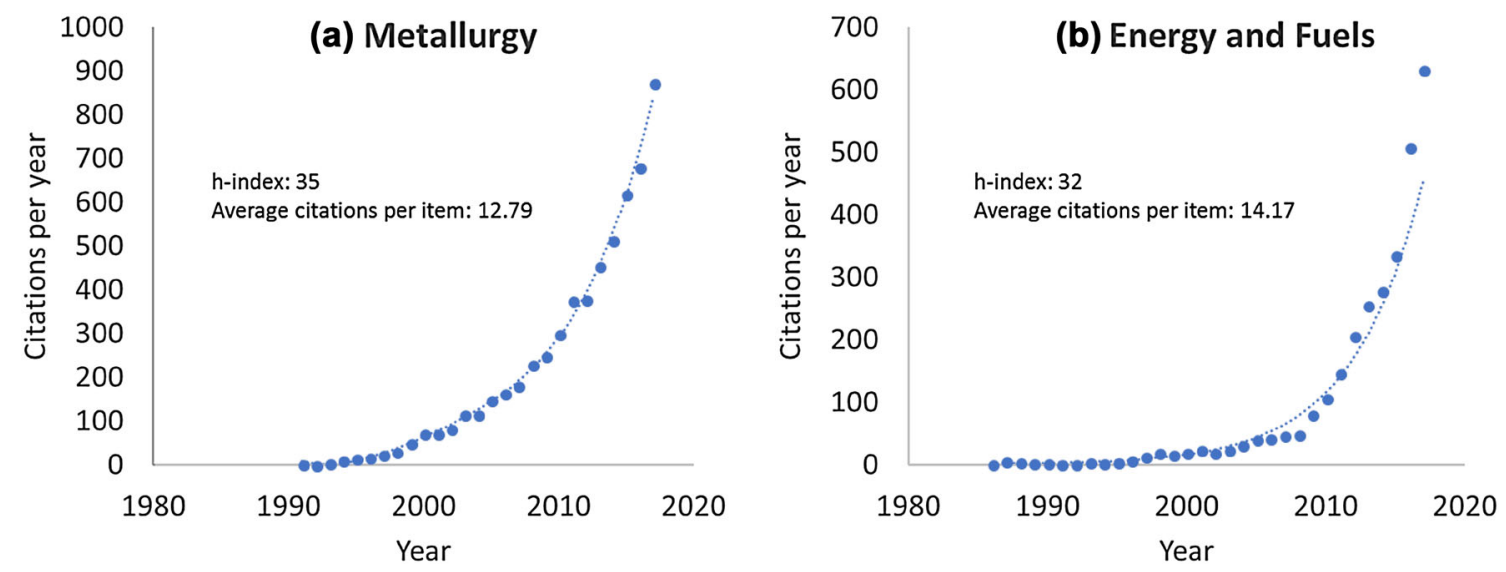

Fig. 1. The citation numbers of papers per year featuring real-time optical imaging techniques in the fields of (a) Metallurgy and (b) Energy and Fuels.

\section{'ENVIRONMENTAL' CONFOCAL SCANNING LASER MICROSCOPY}

- "High Temperature Confocal Laser Scanning Microscopy Studies of Ferrite Formation in Inclusion-Engineered Steels: A Review" by W. $\mathrm{Mu}$, P. Hedström, H. Shibata, P. G. Jönsson, and K. Nakajima.

\section{ACKNOWLEDGEMENTS}

This technical effort was performed in support of the National Energy Technology Laboratory's ongoing research under RES Contract DE-FE0004000.

\section{DISCLAIMER}

This project was funded by the Department of Energy, National Energy Technology Laboratory, an agency of the United States Government, through a support contract with AECOM. Neither the United States Government nor any agency thereof, nor any of their employees, nor AECOM, nor any of their employees, makes any warranty, expressed or implied, or assumes any legal liability or responsibility for the accuracy, completeness, or usefulness of any information, apparatus, product, or process disclosed, or represents that its use would not infringe privately owned rights. Reference herein to any specific commercial product, process, or service by trade name, trademark, manufacturer, or otherwise, does not necessarily constitute or imply its endorsement, recommendation, or favoring by the United States Government or any agency thereof. The views and opinions of authors expressed herein do not necessarily state or reflect those of the United States Government or any agency thereof. 